maintenance of chronic inflammation. Consequently, NIK may be an attractive therapeutic target.

Disclosure of Interest: K. Jeucken: None declared, P. Kucharzewska Employee of: AstraZeneca, C. Maracle: None declared, J. P. van Hamburg: None declared, H. Olsson Employee of: AstraZeneca, S. Tas: None declared DOI: 10.1136/annrheumdis-2018-eular.3413

\section{OP0169 A COMBINATION OF PROTEINS AS MEASURED WITHIN THE MULTI-BIOMARKER DISEASE ACTIVITY SCORE AT PRESENTATION OF RA IDENTIFIES A GROUP OF ACPA-NEGATIVE RA PATIENTS WITH HIGH LIKELIHOOD OF DEVELOPING DMARD-FREE SUSTAINED REMISSION}

D.M. Boeters, L.E. Burgers, T.W. Huizinga, A.H. van der Helm-van Mil. Rheumatology, Leiden University Medical Center, Leiden, Netherlands

Background: Rheumatoid arthritis (RA) typically requires lifelong treatment However, some RA patients achieve sustained disease-modifying antirheumatic drug (DMARD)-free remission, which is a proxy for cure of RA that has become increasingly achievable, as reported previously. DMARD-free sustained remission has been reported mostly in autoantibody-negative RA, yet the underlying mechanism is unknown. The multi-biomarker disease activity (MBDA) score combines 12 serum biomarkers and is developed to measure RA disease activity. We hypothesise that the subgroup of RA patients that is most likely to achieve DMARD-free sustained remission is identifiable at disease presentation by cytokines such as those combined in the MBDA score.

Objectives: To evaluate whether the MBDA score or its component cytokines at the presentation of RA are associated with ability to later achieve DMARD-free sustained remission.

Methods: 300 patients with RA (by the 1987 and/or 2010 criteria) who had been consecutively enrolled in the Leiden Early Arthritis Clinic between 2010 and 2015 were studied. At time of diagnosis, before DMARD treatment was started, the MBDA score, with a scale of 1-100, was determined from the serum concentrations of 12 biomarkers (VCAM-1, EGF, VEGF-A, IL-6, TNF-RI, MMP-1, MMP-3, YKL-40, Leptin, Resistin, CRP, SAA) with a pre-specified, validated algorithm. Patients were categorised as having a low $(<30)$, moderate $e^{30-44}$ or high $(>44)$ MBDA score. DMARD-free sustained remission was defined as the absence of synovitis (by physical examination) that sustained after discontinuation of all DMARD therapy (including biologics and systemic and intra-articular corticosteroids) for the entire follow-up period, but had to extend to at least one year after DMARD withdrawal. Analyses were stratified for ACPA and restricted to 5 years follow-up as thereafter the number of patients became small. The median followup duration of all patients was 4.3 years.

Results: A total of 54 RA patients (18\%) had achieved DMARD-free sustained remission. For the total group of RA patients, baseline MBDA category $(p=0.03)$ and ACPA-negativity $(p<0.001)$ were associated with achieving DMARD-free sustained remission. For ACPA-positive RA patients, the MBDA category at baseline was not associated with achieving DMARD-free sustained remission ( $p=0.89$, figure 1). By contrast, among ACPA-negative RA patients, none of those with low MBDA score achieved DMARD-free sustained remission during 5 years followup, whereas the estimated rate of remission was $50 \%$ for those with moderate or high MBDA scores ( $p=0.009$, figure 1). Of the 12 biomarkers in the MBDA test, only SAA showed a significant difference between ACPA-negative patients with and without DMARD-free sustained remission $(p=0.01)$
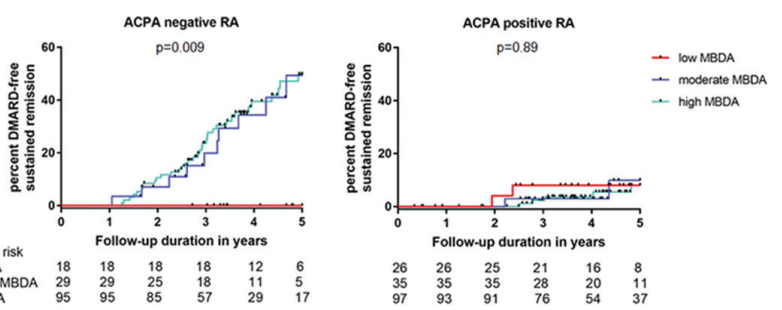

Conclusions: ACPA-negative RA patients who achieved DMARD-free sustained

remission were characterised by moderate to high MBDA scores at disease presentation. This is the first evidence that a cytokine profile at disease onset can identify a subgroup of ACPA-negative RA patients with a high likelihood of maintaining clinical remission after treatment withdrawal.

Disclosure of Interest: None declared DOI: 10.1136/annrheumdis-2018-eular.6209

\section{OP0170 \\ HUMAN IL-38 REDUCES JOINT INFLAMMATION IN A MOUSE MODEL OF GOUTY ARTHRITIS}

D.M. De Graaf ${ }^{1}$, F.L. Van de Veerdonk ${ }^{1}$, E.Z. Eisenmesser ${ }^{2}$, L.A.B. Joosten ${ }^{1}$, C. A. Dinarello ${ }^{1,3} .{ }^{1}$ Experimental Internal Medicine, Radboud University Medical Center, Nijmegen, Netherlands: ${ }^{2}$ Department of Biochemistry and Molecular Genetics; ${ }^{3}$ Department of Medicine, University of Colorado Denver, Aurora, USA

Background: Interleukin-38 (IL-38) is the last member of the IL-1 family of cytokines to be fully investigated for its functions. IL-38 is proposed as an anti-inflammatory cytokine in various auto-inflammatory diseases, such as psoriasis and rheumatoid arthritis. For example, IL-38 knockout mice have exacerbated autoantibody-induced arthritis. Current understanding of the capacity of IL-38 in gout, a prototype IL-1 $\beta$ driven auto-inflammatory disease, is unknown.

Objectives: We hypothesised that in vivo treatment with human recombinant IL 38 results in a reduction in join inflammation in a mouse model of gouty arthritis. Methods: We treated C57/BI6 mice with $1 \mu \mathrm{g}$ recombinant IL-38 (3-152 AA) intraperitoneally at 24, 12 and 2 hours before induction of gouty arthritis with intraarticular injection of albumin-opsonized monosodium urate crystals $(300 \mu \mathrm{g})$ and palmitic acid $(200 \mu \mathrm{M})$ in $10 \mu \mathrm{L}$ PBS. Joint inflammation was scored after 4 hours The synovial lining was cultured in RPMI for 2 hours to allow cytokines to be secreted, and cytokines in the synovium were extracted with Triton-X 100 to obtain total cytokines (membrane and intracellular). In the synovial culture fluid and extract, IL-1 $\beta$, IL-6 and KC were measured by ELISA. Data

Results: Mice treated with recombinant IL-38 exhibited significantly reduced joint swelling and redness on a three-point macroscopic inflammation scale: Vehicletreated $1.5 \pm 0.25$ vs IL-38 Treated $0.75+0.25(n=10, p<0.0001$, Mann Whitney- $U$ test). The 2 hour synovial membrane culture fluid contained significantly lower levels of IL $-1 \beta(1207 \pm 480$ vs $379 \pm 184 \mathrm{pg} / \mathrm{mL}, \mathrm{p}<0.05)$, IL-6 $(10783 \pm 2490$ vs $5321 \pm 2935 \mathrm{pg} / \mathrm{mL}, \mathrm{p}<0.05)$ and $\mathrm{KC}(4390 \pm 931 \mathrm{vs} 1081 \pm 750 \mathrm{pg} / \mathrm{mL}, \mathrm{p}<0.05)$. In extract of the synovial membrane, there is a reduction in IL-1 $\beta(1505 \pm 397$ vs 624 $\pm 509 \mathrm{pg} / \mathrm{mL}, \mathrm{p}<0.05), \mathrm{IL}-6(11059 \pm 2299$ vs $3597 \pm 2509 \mathrm{pg} / \mathrm{mL}, \mathrm{p}<0.01)$ and $\mathrm{KC}$ (1505 \pm 397 vs $624 \pm 509 \mathrm{pg} / \mathrm{mL}, \mathrm{p}<0.05)$

Conclusions: Human recombinant IL-38 reduces swelling and redness of the joint, and pro-inflammatory cytokines secreted by and contained in the synovial membrane in a mouse model of gouty arthritis. These data reveal that recombinant IL-38 has therapeutic benefit in an IL $-1 \beta$ mediated model of inflammation.

Disclosure of Interest: None declared

DOI: 10.1136/annrheumdis-2018-eular.5599

\begin{tabular}{|l|l}
\hline OP0171 & LEPTIN LEVELS, OVERWEIGHT AND P GINGIVALIS \\
PRESENCE CONTRIBUTE TO THE MECHANISM OF \\
SYSTEMIC INFLAMMATION IN FIRST-DEGREE \\
RELATIVES OF RHEUMATOID ARTHRITIS INDIVIDUALS
\end{tabular}

$\underline{\text { C Romero-Sanchez }}^{1,2,3}$, J.A. Chaparro-Sanabria ${ }^{2,3}$, J.M. Bello-Gualtero ${ }^{2,3}$, R. Valle-Oñate ${ }^{3}$, L. Chila ${ }^{1}$, D.M. Castillo ${ }^{1}$, G. Lafaurie ${ }^{1}$, P. Chalem $\mathrm{Ch}^{4}$, W. Bautista-Molano ${ }^{1,2}$. 1 Unit of Oral Basic Investigation, Universidad El Bosque; ${ }^{2}$ Clinical Immunology Group, Universidad Militar Nueva Granada; ${ }^{3}$ Department of Rheumatology and Inmunology, Hospital Militar Central; ${ }^{4}$ Fundación Instituto de Reumatología Fernando Chalem, Bogotá D.C., Colombia

Background: Association studies in rheumatoid arthritis (RA) have been focused in the pre-clinical phases of the disease in first-degree relatives (FDR). Data has shown that obesity, ACPA and the periodontal condition may modulate the severity and the clinical presentation of RA

Objectives: To investigate the levels of adipokines in FDR and establish their association with the state of rheumatic and periodontal condition

Methods: 124 FDR individuals and 124 healthy controls matched by age and gender were included. Rheumatologic (clinical and serological markers) and periodontal assessment was performed. It was quantified the adiponectin, leptin, IL6 levels. HLA-DRB1 was determined. Serum markers of RA (rheumatoid factor, erythrocyte sedimentation rate, $C$ reactive protein (CRP), and APCA. $P$ gingivalis and IgG1/lgG2 $P$ gingivalis were measured. Radiographs of hands and feet were evaluated the Sharp-van der Heijde score. An association analysis was made to evaluate the relationship between adipokines and periodontal, rheumatologic conditions using X2 test, and logistic regression model was performed to confirm this associations

Results: In FDR group, $71.77 \%$ were women with a mean age of $39.24 \pm 12.22$ years. $37.09 \%$ had overweight and $4.83 \%$ had obesity. Among the controls, $70.97 \%$ were women, with an average age of $39.31 \pm 12.30$ years. $27.41 \%$ had overweight and $4.83 \%$ had obesity. Leptin levels were found in $37.66 \%$ vs $18.42 \%$ in controls $(\mathrm{p}=0.002)$. In FDR, $60.48 \%$ had periodontal disease of which $62.66 \%$ moderate, $P$ gingivalis in $62.10 \%$. In controls, $55.64 \%$ had periodontal disease, of which $63.76 \%$ moderate with $42.74 \% P$ gingivalis positive $(p=0.002)$. In the FDR radiography of hands and feet showed in $25.28 \%$ of them had some alteration, $68.18 \%$ had $\geq 1$ erosion, $45.45 \%$ had $\geq 1$ joint space narrowing and in $6.89 \%$ jux taarticular osteopenia. An association of leptin levels with the low economic leve was found $p=0.006$ and high levels of leptin in individuals with $B M I \geq 30 p=0.031$ 
IL6 was found to be associated with severity of periodontal disease, with higher levels being found frequently in mild periodontal disease $p=0.039$. The condition of FDR was significantly associated with high leptin levels adjusted for presence of swollen joints, presence of $P$ gingivalis and low levels of IL6 OR=2,57, 95\% Cl: 1.14 to 5.95 . In this group, the individual with leptin at moderate levels adjusted with $\mathrm{BMI}>25$, has a lower probability of presenting CRP $>3 \mathrm{mg} / \mathrm{L}$ OR $=0.43$ 95\% Cl: 0.20 to 0.90 .

Conclusions: High levels of leptin, the presence of $P$ gingivalis and swollen joints may be relevant conditions associated with the development of RA in FDR.Leptin levels and overweight can modulate the production of acute phase proteins in this group of individuals contributing to the mechanism of systemic inflammation. The clinical implications of our findings propose regulated exercise programs, oral hygiene, and weight control in FDR

\section{REFERENCE:}

[1] Unriza-Puin S, et al. Clin Rheumatol 2017;28(36):799-806.

Disclosure of Interest: None declared

DOI: 10.1136/annrheumdis-2018-eular.3166

\section{OP0172 LPS-INDUCED PERIODONTITIS PROMOTES ARTHRITIS DEVELOPMENT IN MICE}

A. Scanu ${ }^{1}$, C. Giraudo ${ }^{2}$, F. Galuppini ${ }^{3}$, V. Lazzarin ${ }^{3}$, G. Pennelli ${ }^{3}$, S. Sivolella ${ }^{4}$, F. Oliviero ${ }^{1}$, P. Galozzi ${ }^{1}$, M. Rugge ${ }^{3}$, R. Stramare ${ }^{2}$, R. Luisetto ${ }^{5}$, L. Punzi ${ }^{1}$.

${ }^{1}$ Rheumatology Unit, ${ }^{2}$ Radiology Unit, ${ }^{3}$ Surgical Pathology Unit, ${ }^{4}$ Dentistry Section; ${ }^{5}$ Dept. of Surgical Oncological and Gastroenterological Sciences, University of Padova, Padova, Italy

Background: Although in vivo studies have demonstrated that periodontitis aggravates experimental arthritis, there are no animal models that mimic the cooccurrence of these diseases.

Objectives: To investigate the arthritogenic effect of lipopolysaccharide (LPS) in a mouse model of periodontal disease.

Methods: Periodontitis was induced in CD1 mice by injection of 0.01 or $0.05 \mu \mathrm{g}$ of LPS in $5 \mu \mathrm{l}$ of PBS every 48 hour into the vestibular gingiva of the second molar on the left maxilla. Untreated mice or injected with LPS at the tail were used as controls. Mice ( $n=10$ per condition) were monitored daily and arthritis was estimated by conventional visual scoring method (scale 0-5) and recording the paw swelling with a calliper. 2 weeks after the 9th injection mice were sacrificed to collect blood, maxilla and paw samples. The left maxilla was analysed by microCT and the alveolar bone loss was assessed measuring the distance between the cementum-enamel junction (CEJ) and the alveolar bone crest $(A B C)$ of each molar. Ultrasound (US) was performed to measure the ankle joint space. Periodontal and paw tissues were processed for histological analysis. Inflammation, vascular proliferation and bone resorption were scored $(0-3)$ in maxilla. Inflammation, pannus formation, cartilage and bone destruction were scored (0-5) in ankle joints. CXCL1, IL-1 $\beta$, IL-6 and TNF serum levels were determined by ELISA

Results: Ankle swelling and inflammation were noted after the 5th periodontal injection of $0.05 \mu \mathrm{g}$ of LPS, picked at day 18 and continued for the next 15 days with paw swelling and score higher than those of untreated mice (at the sacrifice $\mathrm{p}<0.001)$. $0.01 \mu \mathrm{g}$ of LPS did not induce paw changes. Therefore, the subsequent assessments were conducted only in mice injected with $0.05 \mu \mathrm{g}$ of LPS. The CEJ$A B C$ distance was greater in the inoculated $(0.29 \pm 0.08 \mathrm{~mm})$ than in the control $(0.17 \pm 0.05 \mathrm{~mm})$ mice $(\mathrm{p}<0.001)$. Histological analysis showed that LPS induced a mild vascular proliferation (score $0.8 \pm 0.42$ ) in periodontal tissue and a substantial alveolar bone resorption (score $1.8 \pm 0.42$ ), but not inflammation. US revealed the presence of effusion and a 1.5-fold higher joint space in the ankle of mice with periodontitis than in controls $(p<0.05)$. Leukocyte infiltration (score $2.36 \pm 1.56$ ) and synovial proliferation (score $2.09 \pm 1.54$ ) were observed after histology in ankle joints of mice injected orally. The same sections had slight cartilage (score 1.32 \pm 1.21 ) and bone destruction (score $0.68 \pm 0.72$ ). Animals that received LPS tail injection did not show any clinical and histological signs of arthritis. CXCL1 and TNF were higher in arthritic mice (CXCL1:2226.87 \pm 264.38 pg/ml; TNF:24.55 $\pm 7.0 \mathrm{pg} / \mathrm{ml}$ ), than in controls (CXCL1:445.97 $\pm 92.09 \mathrm{pg} / \mathrm{ml}$; TNF:3.22 $\pm 1.04 \mathrm{pg} /$ $\mathrm{ml})$. Although there was no statistical difference, IL-1 $\beta$ and IL-6 were highest in LPS-mice (IL-1 $\beta: 79.49 \pm 11.99 \mathrm{pg} / \mathrm{ml}$; IL-6:196.02 $\pm 40.62 \mathrm{pg} / \mathrm{ml}$ ).

Conclusions: This study shows that experimental arthritis and periodontal disease can co-occur after LPS oral injection in mice. Our model may be useful to improve the understanding of the mechanisms underlying the link between periodontitis and arthritis.

Disclosure of Interest: None declared

DOI: 10.1136/annrheumdis-2018-eular.2522
THURSDAY, 14 JUNE 2018

\section{Inclusive school environment for young people with RMDs}

\section{OP0173-PARE YOUTH-R-COACH, A PROGRAM FOR YOUTH WITH A CHRONIC DISEASE}

$\underline{L}_{\text {van Nieuwkoop }}^{1,2}$, L. van Geene ${ }^{1}$, R. Janssen ${ }^{1} .{ }^{1}$ Stichting Chronisch Ziek en Werk, Eindhoven; ${ }^{2}$ Stichting Youth-R-Well.com, Lisse, Netherlands

Background: Youth-R-Coach is a project for youth (aged 15-25) with a chronic illness. It is a project set up by the Centre for Chronically III and Work (CCZW) in cooperation with Youth-R-Well.com, the Dutch organisation for youth with RMDs. Youth-R-Coach is based on CCZW's program for the certification of 'experience expertise'.

Objectives: Youth-R-Coach focusses on the development of experts-by-experience, and making those experiences available for others to learn from. A distinctive element is the creative aspect: the development of writing talent.

Methods: The participants reflect individually on personal experiences with their disease, as well as their personal competencies. This process is supported by a portfolio of assignments and a mentor who also has an RMD. The participants also incorporate their personal experience with the disease in a self-written book with support of a writing coach. Even though the process is an individual one, the program starts with a group of participants. There is a kick-off meeting, a weekend training and a final group meeting. In this way, the participants get to know each other and learn from each other's personal experiences with the disease. They stay in contact during the program and help each other with the portfolio and writing of their book. During the meetings, workshops are provided to teach them new skills, such as 'online coaching' and 'presenting'.

Results: Youth-R-Coach worked with a group of 7 participants who followed the program in 2016, and a group of 7 participants who started in 2017. Both groups are currently busy finalising their portfolios and books, which will be ready in May 2018.

The books are intended to make personal experiences in dealing with an RMD available for peers, for whom the books can be a source of support in dealing with the disease. The books are also interesting for a wider audience, because they provide insights into living with a chronic illness as a young person. The books are all very different. Some wrote short columns, while others wrote an entire novel. What all the books have in common is that they are all based on personal experiences of living with a chronic illness.

Developing expertise-by-experience and writing about their experiences has helped the participants to better cope with their disease, and has made them ambassadors. Some of them have been, or are still, involved in activities for patient organisations since the start of the program. For example, some have volunteered as a mentor for an RMD youth holiday camp, or given presentations based on personal experience with an RMD. Some participants will continue coaching their peers after finishing the program, and some continue writing about their personal experiences in a blog. How participants will continue to use their new-found skills is down to personal interests and competencies, but whateve they do, the program has given them useful tools for coping with and teaching others about the disease.

Conclusions: Fourteen participants (aged 18-27) developed their expertise-byexperience in dealing with an RMD and are now able to act as a coach for their peers. Their experiences in dealing with the disease will be published in self-written books and made available to a wide audience. All of the current participants had an RMD, but the project would also be useful for youths who have othe chronic illnesses.

Acknowledgements: Youth-R-Coach was made possible with the financial support of the FNO Foundation.

Disclosure of Interest: None declared

DOI: 10.1136/annrheumdis-2018-eular.1756

THURSDAY, 14 JUNE 2018

\section{The building blocks of systemic inflammation}

\section{OP0174 ALTERATION OF MEDIATORS OF VASCULAR INFLAMMATION BY ANIFROLUMAB IN THE PHASE IIB MUSE STUDY IN SLE}

W.I. White ${ }^{1}$, N.L. Seto ${ }^{2}$, M.P. Playford ${ }^{3}$, K.A. Casey ${ }^{1}$, M.A. Smith ${ }^{1}$, P. Carlucci ${ }^{2}$, B. Yu ${ }^{1}$, L. Wang ${ }^{1}$, G. Illei ${ }^{1}$, N. Mehta ${ }^{3}$, M.J. Kaplan ${ }^{2} .{ }^{1}$ Medlmmune, Gaithersburg; ${ }^{2}$ National Institute of Arthritis and Musculoskeletal and Skin Diseases; ${ }^{3}$ National Heart, Lung, and Blood Institute, Bethesda, USA

Background: Cardiovascular disease remains one of the leading causes of death for patients with systemic lupus erythematosus (SLE), and the disease is 